\title{
INVESTIGATION ON LATERAL RESISTANCE OF JOINTS MADE WITH DRYWALL AND SHEET METAL SCREWS IN BAGASSE PARTICLEBOARD AND COMPARISON WITH THAT OF COMMERCIAL MDF
}

\author{
Saeed Eshaghi ${ }^{1}$, Mahdi Faezipour ${ }^{1}$, Hamid Reza Taghiyariª
}

\begin{abstract}
In this research, effects of screw diameter, screw type, panel type, and end distance on lateral resistance of the joints made with drywall and sheet metal screws were studied in bagasse particleboard and the results were compared to those obtained from commercial medium density fiberboard (MDF). The accuracy of EYM in prediction of lateral resistance was then investigated. The drywall screws comprised of size 8 with coarse thread and size 10 with fine thread; the sheet metal screws comprised of size 8 and 10 with normal thread. Results indicated that lateral resistance increased with the increase in the diameter of both screw types, although not statistically significant. The lateral resistance obtained from MDF specimens was $20 \%$ more than that of bagasse specimens. Increase in the end distance also resulted in an increase in the lateral resistance. In all cases, sheet metal screws showed higher lateral resistance in comparison to those obtained from drywall screws. It can be concluded that Mode III is more accurate than Mode Is in the prediction of lateral resistance in two-member screwed joints (single shear plane) for both MDF and bagasse boards.
\end{abstract}

Keywords: Lateral resistance, European yield model (EYM), medium density fiberboard (MDF), bagasse particleboard, sheet metal screw, drywall screw.

\section{INTRODUCTION}

The stiffness and strength of connections are crucial factors which influence the overall structural behavior. Screw connections have the advantage of being cheaper and easier to make than bonded joints as they require very little preparation, and therefore can be more easily constructed on site. In the American Plywood Association (APA), on the connection of wood elements and its importance, it is noted that a chain is only as strong as its weakest link, and connections are the critical link between elements of a structure. Connections provide load path continuity and ensure structural integrity. When the importance of proper connection details is overlooked, structural failure can occur. Properly designed and detailed connections are what hold a structure together, and the designer needs to understand some fundamental principles associated with connections for wood structures (Williamson 2002). Some studies (Eckelman 1975, 1988, 2003, Erdi et al. 2002, Taghiyari et al. 2012) were conducted on screwed joints in MDF, particleboard, plywood and OSB panels, and heat-treated solid woods, with most of them focusing on screw withdrawal resistance. These studies have revealed that screw withdrawal resistance depended on diameter of screw, corresponding lead hole and the penetration depth of the screw in the main member as well as the density and shear strength parallel to the grain in solid woods; furthermore, internal bond (IB) is a decisive factor in MDF and particleboard.

\footnotetext{
${ }^{1}$ Department of Wood \& Paper Science, Faculty of Natural Resources, The University of Tehran, Karaj, Iran.

${ }^{2}$ Wood Science and Technology Department, The Faculty of Civil Engineering, Shahid Rajaee Teacher Training University, Tehran, Iran htaghiyari@yahoo.com

ACorresponding author: htaghiyari@srttu.edu

Received: 09.03. 2012 Accepted: 22.09. 2012
} 
Lateral resistance of connections with dowel type fasteners was derived from yield limit model known as European Yield Theory or EYM (Aune and Patton-Mallory 1986a,b; Soltis and Wilkinson 1987). Failure mode I was reported to have more accuracy in comparison to failure modes III or V (Haftkhani et al. 2011). They also added that specimens failed in mode $\mathrm{I}_{\mathrm{s}}$ had higher lateral resistance that those cases of failure in mode $\mathrm{III}_{\mathrm{s}}$. Tokuda et al. (1989a,b) performed tests on wood to steel joints made with 9 and $20 \mathrm{~mm}$ in diameter lag screws to compare the influence of loading direction on lateral strength of joints made from softwood timber. They noted that the difference in strengths between the directions parallel and perpendicular to the grain was small for $9 \mathrm{~mm}$ lag screws. For 20$\mathrm{mm}$ diameter lag screw, there was clearly a difference between the two loading directions (average strength ratio was 0.8). Abd-El-Naby (1992) reported that ductile failure of bolted joints could be obtained in the shear mode. The lateral strength of the joints made with small diameter nails is regarded as being unaffected by the direction of loading relative to the grain (Smith et al. 1988, USDA 1999). Ho (1994) stated that resistance and firmness of the joint used in furniture determined its strength and rigidity. Chui et al. (2006) carried out a research on the effect of screw diameter on the lateral resistance of wood screw joint. They found that fracture mode and resistance both depended on screw loading direction and diameter, but the difference between the lateral resistance parallel and perpendicular to the grain (wood member) was relatively increasing along with the increase in the screw diameter.

Based on a theory termed "weakest link" by Weibull, the failure of a specimen will occur when the stress in the specimen is the same as the stress that would cause the failure of the weakest element of volume if tested independently (Gurfinkel 1981, Eckelman 2003); it would therefore be quite necessary to evaluate the strength of joints in furnitures. Taj et al. (2009) measured withdrawal and lateral resistance of wood in beech, hornbeam, and poplar and compared it with calculated values obtained from the existing formulas in the National Design Specification for Wood Construction (NDS) and Eckelman's. They showed that predicted power of withdrawal resistance obtained from Eckelman's suggested Equation was greater than the existing Equation in NDS. In addition, bending yield Equations predicted lateral resistance with high precision and the predicted values in all the three types were smaller than the measured values. Haftkhani et al. (2011) investigated the effect of screw's diameter, pilot hole, end distance, side and main members' thickness, loading rate, and screw type on lateral resistance of screw joints in WPC commercial composites. The results indicated that for the proposed screw diameter, an increase in the end distance, joint member thickness, pilot hole diameter, and loading rate resulted in an increase in the joint's lateral resistance. Screw type did not show any significant effect on the lateral resistance of joints. In addition, they found that the predicted EYM lateral resistance values for the fractured joints in Mode $\mathrm{I}_{\mathrm{s}}$ was more accurate than the fractured joints in Modes III or V. In particleboard and MDF, the ultimate lateral resistance capacity of a screw in single shear plane (two members) was dependent on several factors such as material properties and dimensions of the connection members. These included the panel type and bearing strength of the two joined members and the diameter and yield strength of the screw, etc. In Iran, there are vast resources of bagasse; part of the bagasse is used for particleboard manufacturing. However, little studies have been carried out on the lateral resistance of bagasse particleboards. Therefore, in this study the effects of panel type, screw type, screw diameter, end distance on lateral resistance of screwed joints were investigated on bagasse particleboard and the results were compared with those obtained from the commercial MDF. The predicted lateral resistances according to the failure modes were also compared with the corresponding tested values obtained from the tests.

\section{MATERIALS AND METHODS}

The tests were carried out on bagasse particleboard and commercial MDF; both boards were $16 \mathrm{~mm}$ in thickness (Table 1). The moisture content and density of panels were measured according to EN 322 (2007), EN 323 (2007), internal bonding, modulus of rupture (MOR) and modulus of elasticity (MOE) of them were measured according to EN 319 (2007), EN 310 (2007) and Thickness swelling and Water absorption of them were measured according to EN 317 (2007). In order to investigate the lateral resistance, the bagasse particleboard and MDF specimens were cut according to ASTM D1037 standard (2007). The nominal dimensions of specimens were $200 \times 75 \mathrm{~mm}$ (length $\times$ width). All prepared test joints had a single shear plane (two-member joint) (Fig. 1). Diameter of the pilot hole was $80 \%$ of the root diameter of each screw. The specimens were conditioned for 7 days (relative humidity 
of $65 \pm 1 \%$; and temperature of $20 \pm 2^{\circ} \mathrm{C}$ ). Loading rate was $6 \mathrm{~mm} / \mathrm{min}$. To study the effects of end distance, lateral resistance test was performed at three end distances of 9,12 , and $18 \mathrm{~mm}$ with members to the thickness of $16 \mathrm{~mm}$ both for the main member and side member in both panel types. Variable factors in the lateral resistance test comprised: panel type, screw type, screw diameter, end distance; the constant factors included: joint members thickness, panel density, internal bonding.

Table 1. Physical and mechanical properties of panels

\begin{tabular}{cccccccc}
\hline \hline Panel type & $\begin{array}{c}\text { Moisture } \\
\text { content } \\
(\%)\end{array}$ & $\begin{array}{c}\text { Density } \\
\left(\mathrm{g} / \mathrm{cm}^{3}\right)\end{array}$ & $\begin{array}{c}\text { Water } \\
\text { absorption } \\
(\%)\end{array}$ & $\begin{array}{c}\text { Thickness } \\
\text { swelling } \\
(\%)\end{array}$ & IB(MPa) & $\begin{array}{c}\text { MOE } \\
(\mathrm{MPa})\end{array}$ & $\begin{array}{c}\text { MOR } \\
(\mathrm{MPa})\end{array}$ \\
\hline \hline $\begin{array}{c}\text { Bagasse } \\
\text { particleboard }\end{array}$ & 6.24 & 0.6 & 76.88 & 11.7 & 0.66 & 3308 & 25.25 \\
\hline MDF & 7.11 & 0.7 & 14.3 & 6.42 & 0.8 & 4432 & 36.13 \\
\hline \hline
\end{tabular}

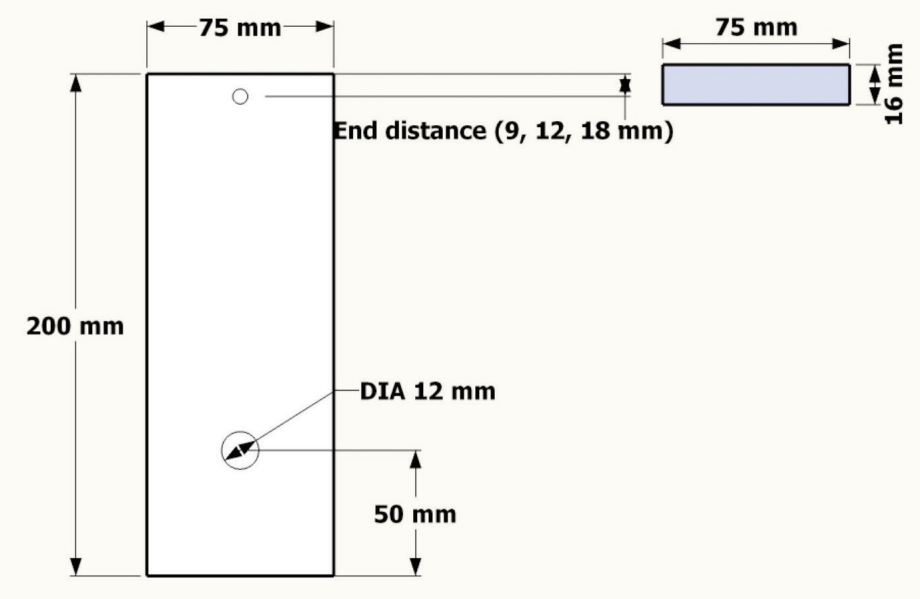

Figure 1. A Schematic drawing of the constructed specimens for load application

Three types of screws were used: sheet metal screws (sizes 8 and 10, with normal thread), drywall screw size 8 with coarse thread, and drywall screw size 10 with fine thread (Fig. 2). Major specifications of these screws are given in table 2. Five replicates for each treatment were tested. 
Table 2. Specifications of screws in this study

\begin{tabular}{lccccc}
\hline \hline Screw type & Screw gauge & $\begin{array}{c}\text { Nominal } \\
\text { diameter }(\mathrm{mm})\end{array}$ & $\begin{array}{c}\text { Actual } \\
\text { diameter }(\mathrm{mm})\end{array}$ & $\begin{array}{c}\text { Root diameter } \\
(\mathrm{mm})\end{array}$ & Thread type \\
\hline \hline Drywall & 8 & 4 & 4.2 & 2.6 & coarse \\
Drywall & 10 & 5 & 4.6 & 2.9 & fine \\
Sheet metal & 8 & 4 & 4.2 & 3 & normal \\
Sheet metal & 10 & 5 & 4.8 & 3.3 & normal \\
\hline \hline
\end{tabular}

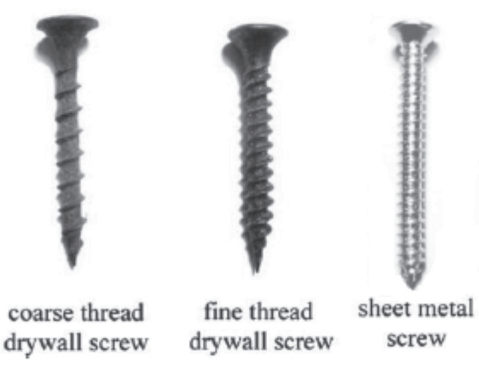

Figure 2. Types of screws in the present study, including coarse thread drywall screw, fine thread drywall screw, and sheet metal screw

The accuracy of the European Yield Model (EYM) in prediction of the lateral resistance was investigated by comparison between the observed lateral resistance values with those obtained by calculation using Equations 1 through 5 (Williamson 2002). The EYM provides three possible failure modes for a two-member screwed connection in single shear (Equations 1- 3). Equations 4 and 5 were used to complete Equations 1-3. The three yield modes (Fig. 3) and the corresponding Equations (1-3) that provide the nominal lateral resistance value for each yield mode are as follows:

$$
\begin{array}{cc}
Z=\frac{D t_{s} F_{e s}}{K_{D}} & \text { Mode } \mathrm{I}_{\mathrm{s}} \\
Z=\frac{k_{3} D t_{s} F_{e m}}{K_{D}\left(2+R_{e}\right)} & \text { Mode III } \mathrm{s} \\
Z=\frac{D^{2}}{K_{D}} \sqrt{\frac{2 F_{e m} F_{y b}}{3\left(1+R_{e}\right)}} & \text { Mode IV } \\
k_{3}=-1+\sqrt{\frac{2\left(1+R_{e}\right)}{R_{e}}+\frac{2 F_{y b}\left(2+R_{e}\right) D^{2}}{3 F_{e m} t_{s}^{2}}} & \\
R_{e}=F_{e m} / F_{e s} &
\end{array}
$$


Where:

$\mathrm{t}_{\mathrm{s}}$ is the side member thickness (in)

$\mathrm{F}_{e m}$ is dowel bearing strength of main member (Psi)

$\mathrm{F}_{\mathrm{es}}$ is dowel bearing strength of side member (Psi)

$\mathrm{F}_{\mathrm{vb}}$ is bending yield strength of screw (Psi)

$\mathrm{D}$ is unthreaded shank diameter of screw (in), or is the root diameter of the threaded portion of the screws when the thread length is such that the threads will extend into the shear plane of the connection (in)

$\mathrm{K}_{\mathrm{D}}=2.2$ for $\mathrm{D} \leq 0.17$ in

$\mathrm{K}_{\mathrm{D}}=10 \mathrm{D}+0.5$ for 0.17 in $<\mathrm{D}<0.25$ in

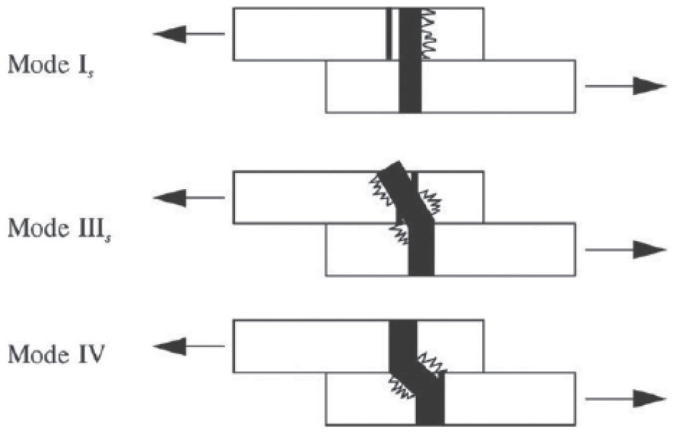

Figure 3. Three possible failure modes for a two-member screw connection in single shear

(Williamson 2002)

Bearing strength was measured according to ASTM D5764-97a (2007). In this experiment a cylindrical fastener with a smooth surface was used. The fastener's diameter was equal to the shank diameter of the fastener used in the lateral resistance test. Dimensions of the specimen and apparatus of test setup are shown in Fig. $4 \mathrm{a}$ and b. Bending yield strength of drywall and sheet metal screws were measured according to ASTM F1575-03 (2007). Taking into consideration that the load application point was in the middle of the screws, the load was applied on the threaded portion of the drywall and sheet metal screws (Fig. 4c). 


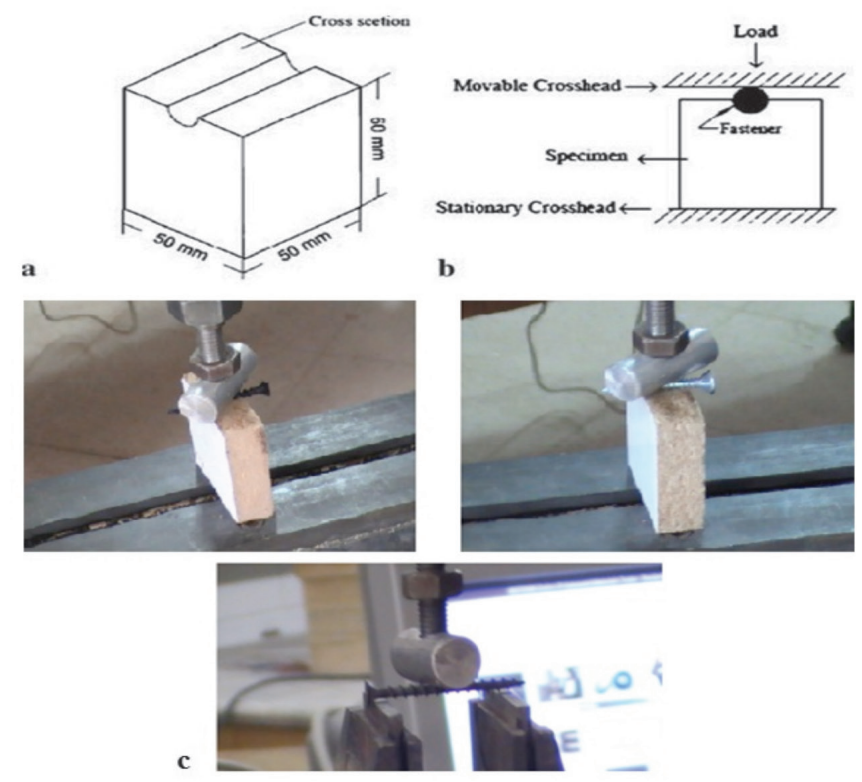

Figure 4. a. Dimensions of dowel bearing strength test. b. A schematic drawing of dowel bearing strength test setup. c. Bending yield strength of wood screw test setup

Statistical analysis was conducted using SPSS/16 software program (2007). Two-way analysis of variance (ANOVA) was performed to discern significant difference at the $95 \%$ level of confidence. Grouping was then made between treatments using the Duncan test.

\section{RESULTS AND DISCUSSION}

Lateral resistance values were generally higher in MDF members in comparison to those obtained from bagasse particleboards (Figures 5 and 6). The maximum lateral resistance in bagasse particleboard was $2629.2(\mathrm{~N})$ which was $8.87 \%$ lower than the equivalent treatment in $\operatorname{MDF}(2862.6 \mathrm{~N})$. The minimum lateral resistance in bagasse particleboard was $1413.2(\mathrm{~N})$ which was $18.22 \%$ lower than its equivalent treatment in MDF (1670.8 N). Sheetmetal screws showed a general higher lateral resistance values in comparison to the drywall screws. No particular trend was observed when screw size was increased in both screw types. 


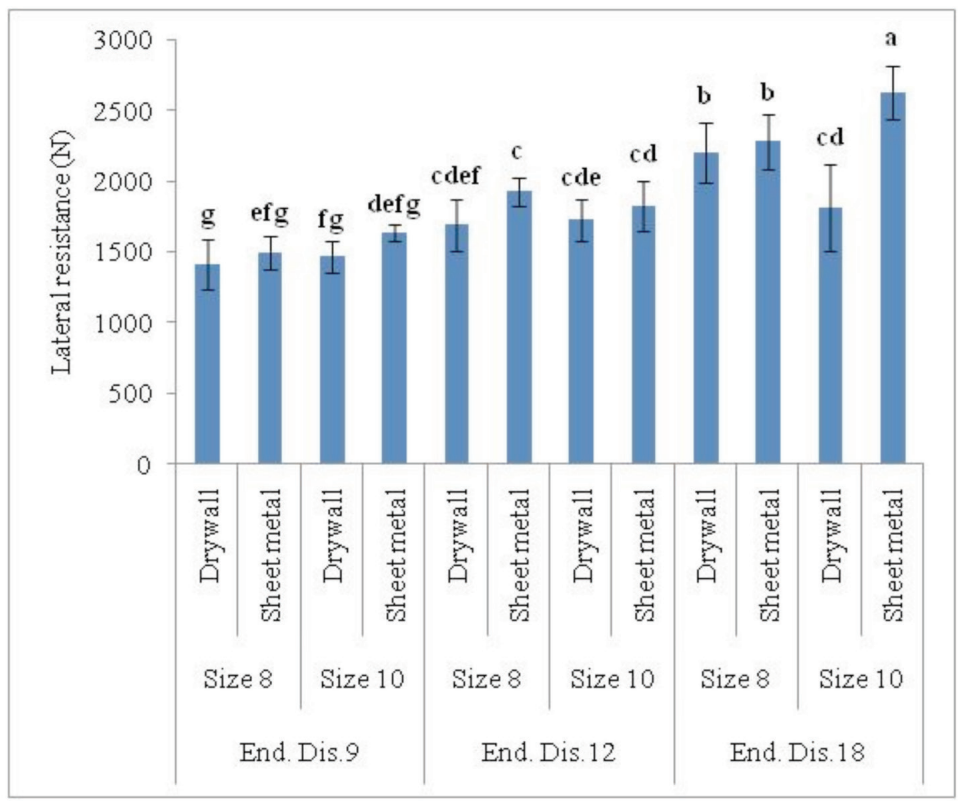

Figure 5. Lateral resistance $(\mathrm{N})$ of the twelve treatments of bagasse particleboard (End.Dis. $=$ End Distance)

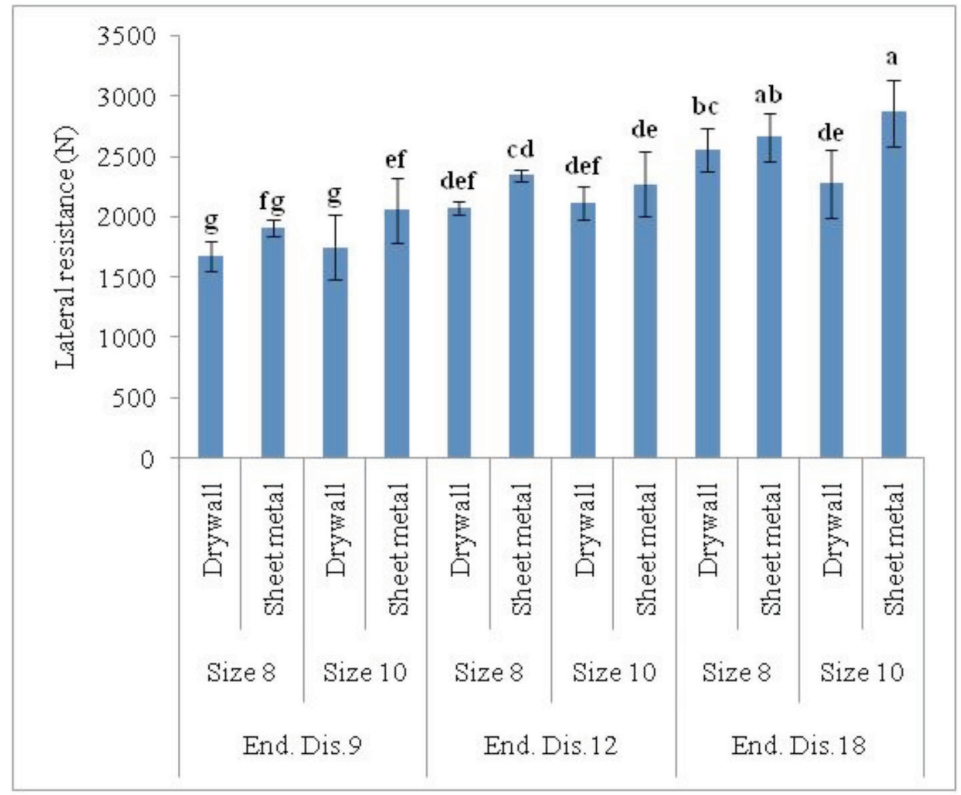

Figure 6. Lateral resistance $(\mathrm{N})$ of the twelve treatments of medium-density fiberboard $(\mathrm{MDF}=$ medium-density fiberboard; End.Dis. $=$ End Distance $)$ 


\section{Effect of screw type on lateral resistance}

Figure 7 illustrates the independent effect of screw type on the lateral resistance. The lateral resistance of sheet metal screw was $14.2 \%$ higher than that of drywall screw. The thickness of the joint members was $16 \mathrm{~mm}$ for all the tests in the present study. At a given gauge number, the root diameter of sheet metal screw was higher than its equivalent drywall screw. This can be considered the reason why the lateral resistances of sheet-metal screws were higher than those of drywalls screws. The lateral resistance of coarse thread drywall screw was also higher than that of fine thread drywall screws. This could be attributed to the higher height of threads in coarse thread drywall screws. It may be concluded that screw type significantly influence the lateral resistance.

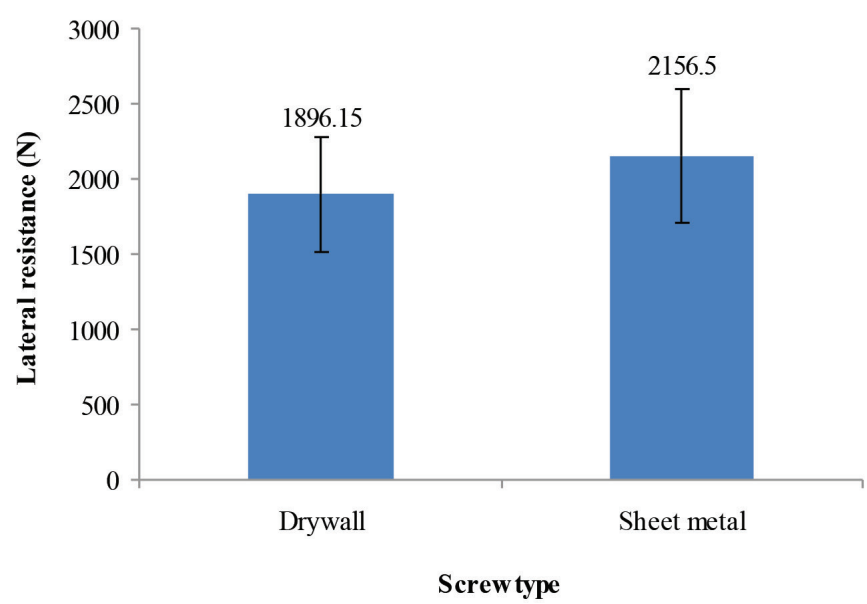

Figure 7. Independent effect of screw type on the lateral resistance of two types of screws (the lateral resistance values are the mean values obtained from all twelve treatments)

\section{Effect of screw diameter on lateral resistance}

Figure 8 shows the independent effect of screw diameter on the lateral resistance (the lateral resistance values shown in the Figures are the mean values of all treatments). Increase in the screw diameter resulted in an increase in the lateral resistance, although not significantly (only about $0.8 \%$ ). This increase can be attributed to the increase in the connecting surfaces between the screw and the joint members. Sheet-metal screws showed higher lateral resistance in comparison to drywall screws (Fig. 9). The reason can be traced to the more root diameter in sheet-metal screws.

Considering only the drywall screws with two different sizes of 8 and 10 (4 and 5), the lateral resistance of drywall screw size 4 showed higher values (Fig. 9), although not significantly different. The type of thread was the source of this difference; that is, drywall screw size 8 was coarse thread, while drywall screw size 10 was fine thread. The threads in the coarse type was longer, causing better penetration and involvement in the joint members, resulting in the improvement in the lateral resistance values. 


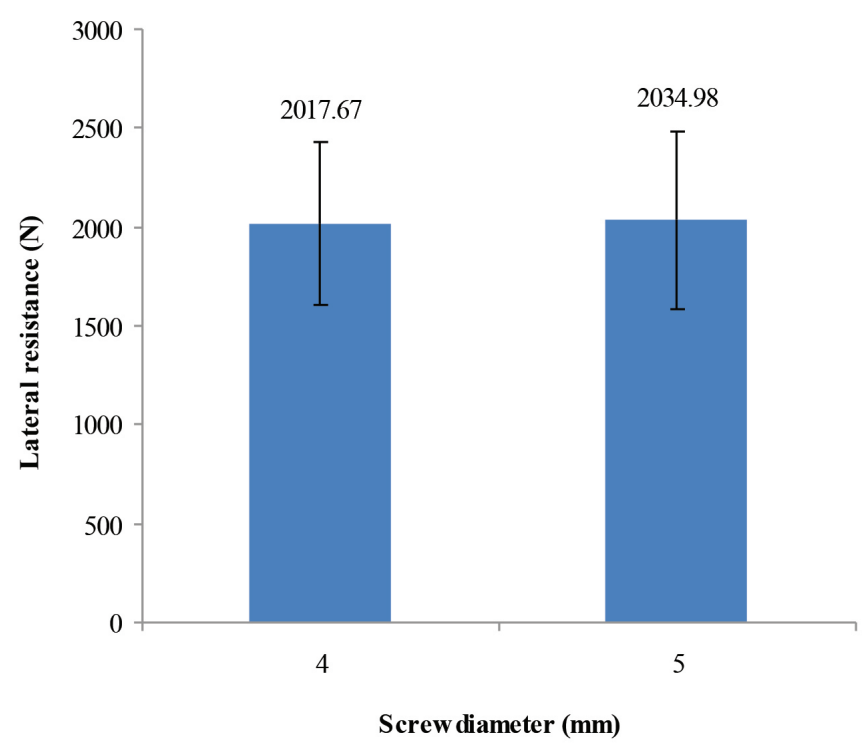

Figure 8. Independent effect of screw diameter on lateral resistance

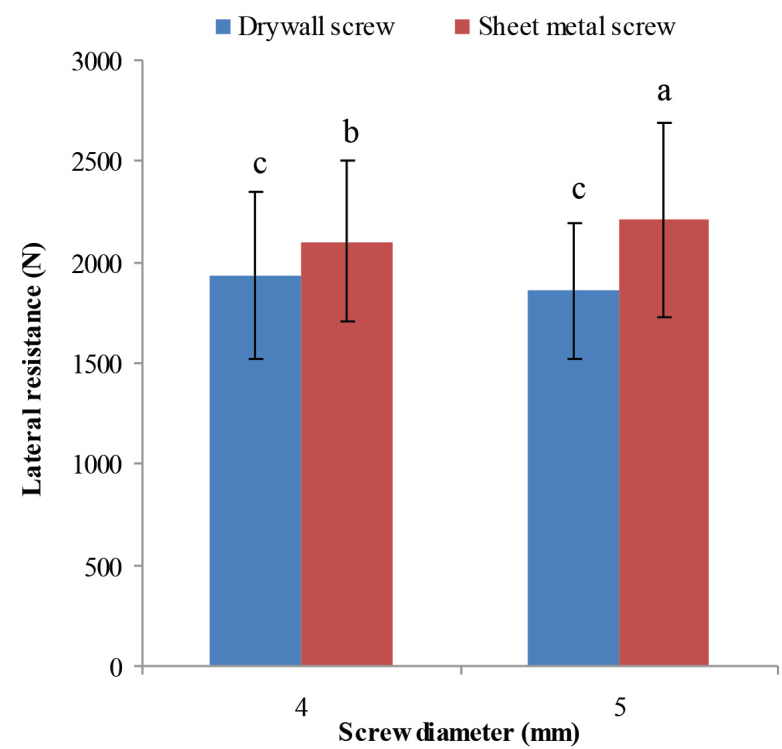

Figure 9. Correspondıng eftect ot screw diameter and screw type on lateral resistance

\section{Effect of end distance on lateral resistance}

Increase in the end distance resulted in a significant increase in the lateral resistance (Fig. 10). End distance of 12 and $18 \mathrm{~mm}$ showed 19 and $44 \%$ of increase, respectively, in comparison to end distance of $9 \mathrm{~mm}$. In fact, the increase in the end distance caused more fibers in the body of joint members to be involved in the test, resulting in greater lateral resistance values. The higher lateral resistance of sheet-metal screws in comparison to drywall screws can be attributed to higher root diameter of sheet-metal screws (Fig. 11). 


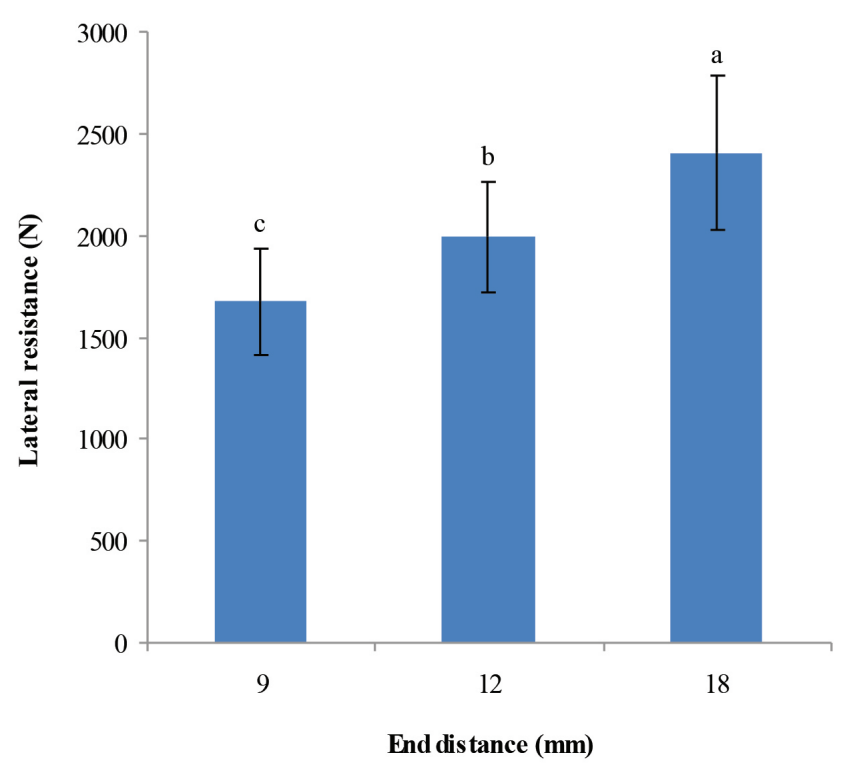

Figure 10. Independent effect of end distance on lateral resistance

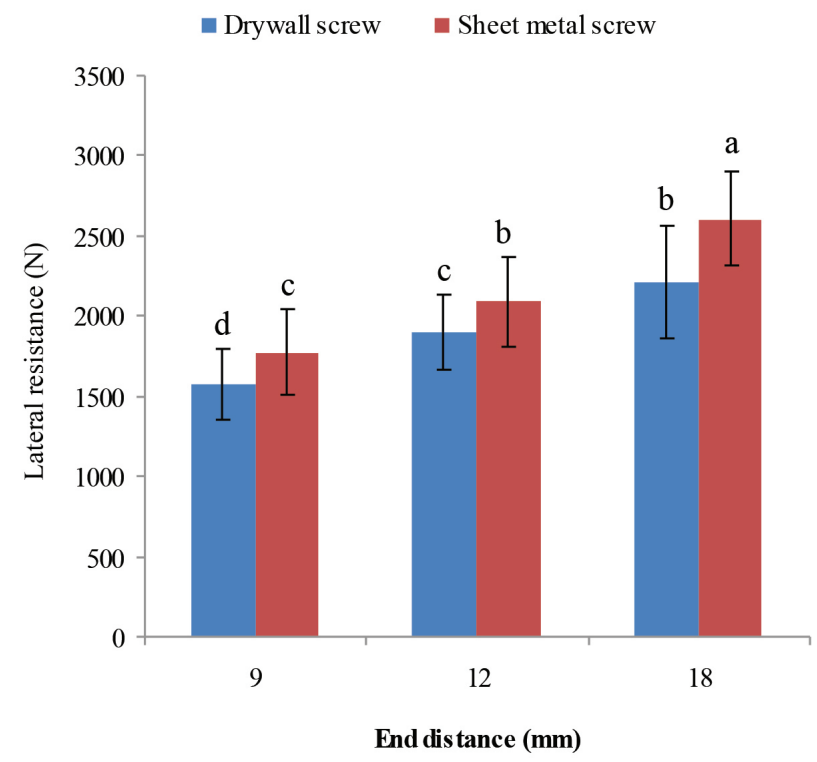

Figure 11. Corresponding effect of end distance and screw type on lateral resistance

\section{Effect of panel type on lateral resistance}

Independent effect of panel type showed an overall higher value of $20 \%$ in MDF specimens in comparison to those made by bagasse particleboards (Fig. 12). The significant difference in the mechanical properties of MDF and bagasse particleboard can be considered as the main reason (Table 1). It may be concluded that the overall lateral resistance of joints can not only be contributed to the screw type and diameter, as well as the end distance, but also the joint members can play a significant role in this part. 


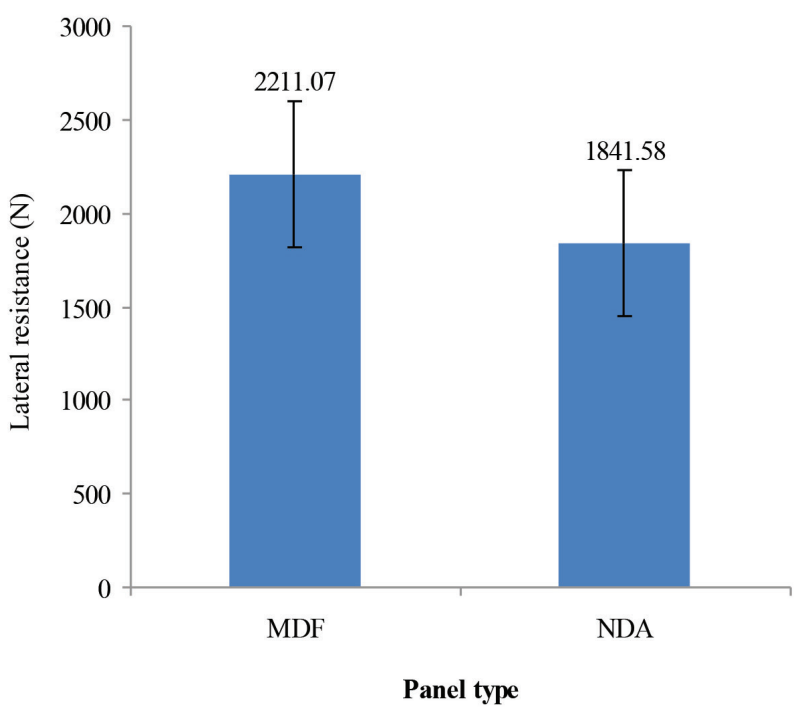

Figure 12. Independent effect of panel type on lateral resistance

\section{Accuracy of the European Yield Model (EYM)}

The accuracy of the European Yield models (EYM) was investigated by the comparison between the observed values by the tests with those theoretically obtained by the Equations $1-5$ (Table 3 ). As a general rule, the less the absolute values for MAE are, the more accurate the prediction for the lateral resistance would be. The MAE values obtained by mode III were generally less than those obtained by mode $\mathrm{I}_{\mathrm{s}}$. It can therefore be concluded that predicting the lateral resistance in EYM method by mode $\mathrm{III}_{\mathrm{s}}$ would be more accurate than mode $\mathrm{I}_{\mathrm{s}}$.

Different end distances resulted in significant difference in the lateral resistance (Fig. 11). However, in neither of the Equations in the EYM models, the end distance values are included. This can justify the high standard deviation in the MAE values (Table 3). It may therefore be concluded that EYM models may not be suitable in the prediction of the lateral resistance for MDF and bagasse particleboards. 
Table 3. The comparison between the observed and calculated values of lateral resistance with corresponding failure modes (thickness for the side and main members in all specimens were $16 \mathrm{~mm}$ )

\begin{tabular}{|c|c|c|c|c|c|c|c|c|}
\hline $\begin{array}{l}\text { Panel } \\
\text { type }\end{array}$ & Screw type & $\begin{array}{c}\text { Screw } \\
\text { size }\end{array}$ & $\begin{array}{c}\text { End } \\
\text { distance } \\
(\mathrm{mm})\end{array}$ & $\begin{array}{l}\text { Failure } \\
\text { modes }\end{array}$ & $\begin{array}{l}\text { Observed } \\
\text { value }(\mathrm{N})\end{array}$ & $\begin{array}{l}\text { Calculated } \\
\text { value }(\mathrm{N})\end{array}$ & MAE & $\begin{array}{c}\text { Fracture } \\
\text { type of } \\
\text { member }\end{array}$ \\
\hline Bagasse & Sheet metal & $10(5)^{*}$ & 9 & $\mathrm{I}_{\mathrm{s}}$ & 1635.8 & 4064.9 & 2429.1 & cleavage \\
\hline Bagasse & Sheet metal & $10(5)$ & 12 & $\mathrm{I}_{\mathrm{s}}$ & 1821.6 & 4064.9 & 2243.3 & cleavage \\
\hline Bagasse & Sheet metal & $10(5)$ & 18 & $\mathrm{I}_{\mathrm{s}}$ & 2629.2 & 4064.9 & 1435.7 & cleavage \\
\hline Bagasse & Sheet metal & $8(4)$ & 9 & $\mathrm{III}_{\mathrm{s}}$ & 1492.4 & 1925.9 & 433.5 & cleavage \\
\hline Bagasse & Sheet metal & $8(4)$ & 12 & $\mathrm{III}_{\mathrm{s}}$ & 1925.4 & 1925.8 & 0.58 & cleavage \\
\hline Bagasse & Sheet metal & $8(4)$ & 18 & $\mathrm{III}_{\mathrm{s}}$ & 2277.4 & 1925.9 & 351.5 & cleavage \\
\hline Bagasse & Drywall & $10(5)$ & 9 & $\mathrm{III}_{\mathrm{s}}$ & 1469 & 2823.4 & 1354.4 & cleavage \\
\hline Bagasse & Drywall & $10(5)$ & 12 & $\mathrm{III}_{\mathrm{s}}$ & 1728 & 2823.4 & 1095.4 & cleavage \\
\hline Bagasse & Drywall & $10(5)$ & 18 & $\mathrm{III}_{\mathrm{s}}$ & 1812.4 & 2823.4 & 1011 & cleavage \\
\hline Bagasse & Drywall & $8(4)$ & 9 & $\mathrm{III}_{\mathrm{s}}$ & 1413.2 & 2087.79 & 674.5 & cleavage \\
\hline Bagasse & Drywall & $8(4)$ & 12 & $\mathrm{III}_{\mathrm{s}}$ & 1689 & 2087.7 & 398.7 & cleavage \\
\hline Bagasse & Drywall & $8(4)$ & 18 & $\mathrm{III}_{\mathrm{s}}$ & 2205 & 2087.7 & 117.3 & cleavage \\
\hline MDF & Sheet metal & $10(5)$ & 9 & $\mathrm{I}_{\mathrm{s}}$ & 2053.2 & 4064.9 & 2011.7 & cleavage \\
\hline MDF & Sheet metal & $10(5)$ & 12 & $\mathrm{I}_{\mathrm{s}}$ & 2269.2 & 4064.9 & 1795.7 & cleavage \\
\hline MDF & Sheet metal & $10(5)$ & 18 & $\mathrm{I}_{\mathrm{s}}$ & 2862.6 & 4064.9 & 1202.3 & cleavage \\
\hline MDF & Sheet metal & $8(4)$ & 9 & $\mathrm{I}_{\mathrm{s}}$ & 1910.4 & 2652.1 & 741.7 & cleavage \\
\hline MDF & Sheet metal & $8(4)$ & 12 & $\mathrm{I}_{\mathrm{s}}$ & 2343.2 & 2652.1 & 308.92 & cleavage \\
\hline MDF & Sheet metal & $8(4)$ & 18 & $\mathrm{I}_{\mathrm{s}}$ & 2657.6 & 2652.1 & 5.5 & cleavage \\
\hline MDF & Drywall & $10(5)$ & 9 & $\mathrm{III}_{\mathrm{s}}$ & 1748.8 & 2823.4 & 1074.6 & cleavage \\
\hline MDF & Drywall & $10(5)$ & 12 & $\mathrm{III}_{\mathrm{s}}$ & 2114.6 & 2823.4 & 708.8 & cleavage \\
\hline MDF & Drywall & $10(5)$ & 18 & $\mathrm{III}_{\mathrm{s}}$ & 2276.4 & 2823.4 & 547 & cleavage \\
\hline MDF & Drywall & $8(4)$ & 9 & $\mathrm{III}_{\mathrm{s}}$ & 1670.8 & 2087.7 & 416.9 & Cleavage \\
\hline MDF & Drywall & $8(4)$ & 12 & $\mathrm{III}_{\mathrm{s}}$ & 2072.8 & 2087.7 & 14.9 & Cleavage \\
\hline MDF & Drywall & $8(4)$ & 18 & $\mathrm{III}_{\mathrm{s}}$ & 2554.2 & 2087.79 & 466.5 & Cleavage \\
\hline
\end{tabular}

* The first figure is the screw size, and the figure in brackets is the diameter of the screw (mm).

Figure 13 illustrates various types of member fracture modes under lateral resistance. The fracture of MDF and bagasse panels with single shear plane connected with screw may occur both in the screw and side member. EYM considers only screw failure mode. In this study, it was observed that in specimens in which screw failed in modes 
$\mathrm{I}_{\mathrm{s}}$ and III, the fracture of the side member was cleavage type. Results of this section are not consistent with the findings by Haftkhani et al. (2011). It can be attributed to the fact that determination of fracture mode in the side member depended on the material used in the side member; that is, the materials in the present study were MDF and bagasse particleboard, while Haftkhani et al. (2011) used wood-plastic composites (WPC) which improved mechanical and physical properties.
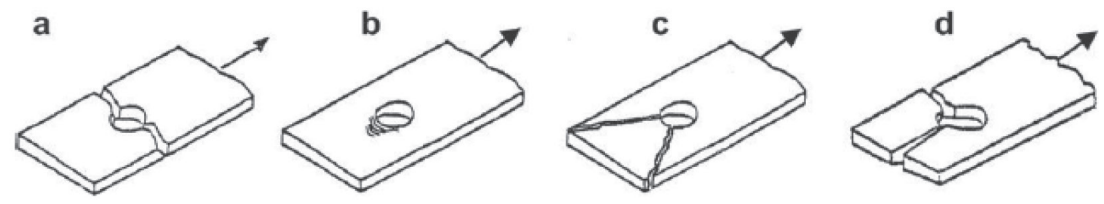

Figure 13. Fracture modes in the side member of MDF and bagasse particleboard panels with single shear plane: (a) lateral (net- tension), (b) bearing, (c) tear-out, and (d) cleavage

(Haftkhani et al. 2011, Thoppul et al. 2009).

\section{CONCLUSION}

In the present research, the effects of screw type, screw diameter, end distance on the lateral resistance of joints made up of drywall and sheet-metal screws in bagasse particleboards were studied and compared with the results obtained from MDF-boards. The accuracy of European Yield Models (EYM) in the prediction of lateral resistance was also investigated. Results indicated that panel type, screw type, and end distance had significant effects on the lateral resistance of two-member screwed joint (single shear plane). However, screw diameter didn't show significant effect on lateral resistance. Lateral resistance in MDF-specimens was about $20 \%$ more than those obtained from bagasse particleboards, proving the effect of the base material in the lateral resistance of joints. Sheet-metal showed about $14.2 \%$ improvement in the lateral resistance when compared with drywall screws, implying the better involvement of the screw threads in the body of specimens. Direct relationship was observed between the end distance with the improvement in the lateral resistance. The EYM assessment showed that Mode III was better in the prediction of lateral resistance than Mode $\mathrm{I}_{\mathrm{s}}$ in two-member screwed joints made of bagasse particleboards or MDF. However, as to the significant effect of end distance on the observed lateral resistance, and also due to the fact that neither of the EYM Equations include end resistance values in their calculations, these models are not recommended in the prediction of lateral resistance. It may be concluded that in cases when the diameter of holes and screws can not be increased due to design aspects, the overall strength of joints can be increased by suitable selection of screw type as well as increase in the end distance.

\section{REFERENCES}

Abd-El-Naby, S. F. M. 1992. Experimental and theoretical investigations of bolted joints for pultruded composite structures, PhD thesis, Dept. of Civil Engineering, University of Surrey.

ASTM. American Society for Testing and Materials. 2007. Standard methods for evaluating properties of wood-base fiber and particle panel materials. ASTM D 1037-96a. Philadelphia.

ASTM. American Society of Testing and Materials. 2007. Standard test method for determining bending yield moment of nails. ASTM F 1575-95.

ASTM. American Society of Testing and Materials. 2007. Test Method for Determining Dowel Bearing Strength of Wood and Wood-Based Products. ASTM D 5764-97a.

Aune, P; Patton-Mallory, M. 1986a. Lateral load-bearing capacity of nailed joints based on the yield theory: theoretical development. U.S. Forest Service Forest Products Laboratory Research Paper FPL 469.

Aune, P.; Patton-Mallory, M. 1986b. Lateral load-bearing capacity of nailed joints based on the yield theory: experimental verification. U.S. Forest Service Forest Products Laboratory Research Paper FPL 470. 
Chui, Y. H.; Smith, L.; Chen, Z. 2006. Influence of fastener size on lateral strength of steel- to- wood screw joints, Fiberboard. Forest Products Journal 56(7-8):49-54.

Eckelman, C.A. 1975. Screw holding performance in hardwoods and particleboard. Forest Products Journal 25(6): $30-35$.

Eckelman, C.A. 1988. The withdrawal strength of screws from a commercially available medium density fiberboard. Forest Prod J 38:21-24.

Eckelman, C.A. 2003. Textbook of product engineering and strength design of furniture. Purdue University Press.

EN. European Standard. 2007. Standard Test Methods for Determination of modulus of elasticity in bending and bending strength. EN 310. German version.

EN. European Standard. 2007. Standard Test Methods for determination of swelling in thickness after immersion. EN 317. German version.

EN. European Standard. 2007. Standard Test Methods for Determination of tensile strength perpendicular to the plane of the board. EN 319. German version.

EN. European Standard. 2007. Wood-based panels; Determination of moisture content. EN 322. German version.

EN. European Standard. 2007. Wood-based panels; Determination of density. EN 323.German version.

Erdil, Y.; Zhang, J.; Eckelman, C.A. 2002. Holding strength of screws in plywood and oriented strandboard. Forest Products Journal 52(6): 55- 62.

Gurfinkel, G. 1981. Wood Engineering, Kendall/Hunt, Dubuque, IA.

Haftkhani, R. A.; Ebrahimi, Gh.; Tajvidi, M.; Layeghi, M.; Arabi, M. 2011. Lateral resistance of joints made with Various Screws in Commercial wood Plastic Composites. Material and Design 32 (7): 4062-4068.

Ho, C.L.; Eckelman, C.A. 1994. The use of performance tests in evaluating joint and fastener strength in case furniture. Forest Products Journal 44(9): 47-53

Smith, L.; Whale, L. R. J.; Anderson, C.; Hilson, B. O.; Rodd, P. D. 1988. Design properties of laterally loaded nailed or bolted joints. Can J Civ Eng 15 (4):633-643.

Soltis, L. A.; Wilkinson, T. A. 1987. Bolted-connection design. U.S. Forest Service Forest Products Laboratory Research Paper. FPLGTR- 54.

Taghiyari, HR; Gholamiyan, H; Karimi, A. 2012. Effects of heat-treatment on screw and nail withdrawal of nanosilver-impregnated and untreated solid woods. Current Nanoscience 8(8): 637- 642.

Taj, M. A.; Najafi, S. K.; Ebrahimi, Gh. 2009. Withdrawal and Lateral resistance of wood Screw in beach, hornbeam and Poplar. Eur J Wood Prod 67: 135-140.

Thoppul, S.; Finegan, J.; Gibson, R. 2009. Mechanics of mechanically fastened joints in polymer-matrix composite structures-a review. Compos Sci Technol 69 (3-4):301-329.

Tokuda, M.; Hirashima, Y.; Matsubara, H. 1989a. The strength of lag-screw joints. I: Lateral strength parallel-to-grain. Journal of Wood Science 35(6): 473-481.

Tokuda, M.; Hirashima, Y.; Matsubara, H. 1989b. The strength of lag-screw joints, II: Lateral strength perpendicular-to-grain. Journal of Wood Science 35(6): 482-488.

USDA Forest Service, Forest Product Laboratory. 1999. Wood Hand-book: Wood as an Engineering Material. Forest Prod. Soc., Madison, WI.

Williamson, T. 2002. APA Engineered Wood Handbook. McGraw-Hill Professional. USA, pp. 750. 